\title{
Temperature Drives Contrasting Alternaria Leaf Spot Epidemic Development in Canola and Mustard Rape from Alternaria japonica and A. brassicae
}

\author{
Hebba F. D. Al-lami, ${ }^{1}$ Ming Pei You, ${ }^{2}$ and Martin J. Barbetti ${ }^{2, \dagger}$ \\ ${ }^{1}$ School of Agriculture and Environment and the UWA Institute of Agriculture, Faculty of Science, The University of Western \\ Australia, Crawley, WA, 6009, Australia; and Department of Biology, Faculty of Science, Mustansiriyah University, Baghdad, \\ Iraq \\ ${ }^{2}$ School of Agriculture and Environment and the UWA Institute of Agriculture, Faculty of Science, The University of Western \\ Australia, Crawley, WA, 6009, Australia
}

Abstract

\begin{abstract}
Recent surveys of canola (Brassica napus) crops across southern Australia highlighted that Alternaria leaf spot on canola is not solely caused by Alternaria brassicae but that other Alternaria spp. are also involved, including A. japonica. Studies were undertaken into the effects of different temperatures $\left(14\right.$ and $10^{\circ} \mathrm{C}$ [day and night] or 22 and $17^{\circ} \mathrm{C}$ [day and night]) on development of Alternaria leaf spot caused by A. japonica as compared with $A$. brassicae in cotyledons (embryonic leaves) and true leaves (first leaves) of canola (B. napus 'Thunder TT') and mustard rape (B. juncea 'Dune'). Both pathogens expressed less disease at lower temperatures of 14 and $10^{\circ} \mathrm{C}$ with percent disease index (\%DI) of 19.1 for $A$. japonica and 41.8 for $A$. brassicae, but expressed significantly more disease at higher temperatures of 22 and $17^{\circ} \mathrm{C}$ with $\%$ DI of 80.8 and 88.2 for the same pathogens, respectively. At 14 and $10^{\circ} \mathrm{C}$, mustard rape cotyledons showed less disease (percent cotyledons disease index $[\% \mathrm{CDI}]=$ 18.1) from A. japonica but showed more disease $(\% \mathrm{CDI}=75.0)$ from A. brassicae. However, at 22 and $17^{\circ} \mathrm{C}$, cotyledons and true leaves of both canola and mustard rape showed significantly more disease and varied in expressing the disease severity to the two pathogens; true leaves
\end{abstract}

of mustard rape showed less disease (percent true leaf disease index $[\% \mathrm{TDI}]=48.4)$ from $A$. japonica but showed more disease $(\% \mathrm{TDI}=$ 92.0) from A. brassicae. At 22 and $17^{\circ} \mathrm{C}$, cotyledons of canola expressed more disease from A. japonica $(\% \mathrm{CDI}=99.1)$ than from A. brassicae $(\% \mathrm{CDI}=70.7)$. At the lower temperature, both host species showed the least disease, with mean \%DI of 27.3 and 33.5 for canola and mustard rape, respectively, as compared with the higher temperatures, where there was a greater DI, with \%DI values of 87.9 and 81.2 for these same host species, respectively. We believe that these are the first studies to highlight the critical role played by temperature for A. japonica as compared with $A$. brassicae in Alternaria leaf spot disease development and severity. These findings explain how temperature affects Alternaria leaf spot severity caused by A. japonica as compared with A. brassicae on different foliage components of canola and mustard rape.

Keywords: Alternaria brassicae, Alternaria japonica, Alternaria leaf spot, Brassica juncea, Brassica napus, canola, mustard rape, temperature
Alternaria leaf spot, caused by Alternaria brassicae, is a major pathogen of oilseed Brassicas (Saharan et al. 2016) and highlighted as a significant issue in Canada (Degenhardt et al. 1974), France (Marchegay et al. 1990), India (Saharan and Kadian 1983), and the United Kingdom (Evans and Gladders 1981). In Lithuania, 87 to $100 \%$ and $100 \%$ of winter and spring oilseed rape siliques (Brassica napus), respectively, can be damaged (Brazauskiene and Petraitiene 2006). In India, reported yield losses in Indian mustard (mustard rape, B. juncea) include 20 to 22\% (Kumar 1997; Prasad et al. 2003 ) and, in Canada, yield losses of $42 \%$ in canola (B. napus) have been reported (Degenhardt et al. 1974). In Australia, Alternaria leaf spot caused by $A$. brassicae has been widely reported on species of Brassicaceae, including in Western Australia on cauliflower (B. oleracea var. botrytis), canola, wild radish (Raphanus raphanistrum) (Shivas 1989), and crambe (Crambe abyssinicia) (You et al. 2005); in Victoria on both canola and mustard rape (Van de Wouw et al. 2016); and in Tasmania on rutabaga (B. napus var. napobrassica) (Sampson and Walker 1982). A. japonica has been reported in Western Australia on wild radish; in New South Wales on canola,

${ }^{\dagger}$ Corresponding author: M. J. Barbetti; martin.barbetti@uwa.edu.au

Funding: A scholarship from the Higher Committee for Educational Development (HCED) and Mustansiriyah University in Iraq was provided to H. F. D. Al-lami, and the School of Agriculture and Environment, University of Western Australia provided financial support of this work.

The author(s) declare no conflict of interest.

Accepted for publication 27 January 2020.

(C) 2020 The American Phytopathological Society mustard rape, and hoary stock (Matthiola incana) (Al-lami et al. 2019a; APPD 2019); and in Victoria on pak-choi (B. chinensis) (APPD 2019). Recent surveys of canola crops across southern Australia highlighted that Alternaria leaf spot on canola across southern Australia is not solely caused by A. brassicae but that a range of other Alternaria spp. are also involved to varying degrees, including $A$. japonica (Al-lami et al. 2019a). Furthermore, the range of Alternaria spp. involved also depends upon the year and the geographic locality (Al-lami et al. 2019a).

A. brassicae, along with A. alternata, A. brassicicola, and A. raphani, cause symptoms across different plant organs, including cotyledons (embryonic leaves), true leaves, petioles, stems, florescences, siliquae, and seed (Humpherson-Jones and Maude 1982; Saharan et al. 2016). In the field, conidia are distributed through the air and by rain splash and the initial infections, that can begin on the cotyledons, become a source for secondary infections across the crop (Verma and Saharan 1994). Providing there is favorable temperature and moisture, the entire crop can become infected (Humpherson-Jones and Maude 1982; Humpherson-Jones and Phelps 1989; Verma and Saharan 1994).

Both temperature and relative humidity $(\mathrm{RH})$, along with the photoperiod, play significant roles in Alternaria leaf spot development caused by A. brassicae (Humpherson-Jones and Phelps 1989; Meena et al. 2010). For example, the severity of Alternaria leaf spot on mustard rape cultivar Varuna leaves under field conditions is correlated with a maximum temperature range of 18 to $27^{\circ} \mathrm{C}$, minimum temperature of 8 to $12^{\circ} \mathrm{C}$, and $>92$ and $40 \% \mathrm{RH}$ morning and afternoon, respectively (Chattopadhyay et al. 2005). However, this can vary with host or host species. For example, on mustard rape, cauliflower, and cabbage (B. oleracea var. capitata), severity of Alternaria leaf spot (A. brassicae) is correlated with average field maximum and minimum temperatures of 10 to 28 and 1.5 to $15.3^{\circ} \mathrm{C}$, respectively 
(Selvamani et al. 2014). On yellow sarson cultivar T-151 (B. campestris) and mustard rape cultivar Varuna, severity of Alternaria leaf spot caused by $A$. brassicae was correlated with maximum and minimum temperatures of 20 to $23^{\circ} \mathrm{C}$ and 7 to $10^{\circ} \mathrm{C}$, respectively, with $>67 \% \mathrm{RH}$, more than six total rainy days, and rainfall $>70 \mathrm{~mm}$ $(r=0.51$ to 0.81 ) (Awasthi and Kolte 1990). In another study on mustard rape cultivar RLM 619, disease development from A. brassicae was most severe across a temperature range of 13.5 to $19.3^{\circ} \mathrm{C}$ with $>70 \%$ RH (Bal and Kumar 2014). Temperature effects have also been reported for other Alternaria spp. such as A. brassicicola, with disease most severe in the spring season $\left(17\right.$ to $32^{\circ} \mathrm{C}$, average daily mean) as compared with the winter season $\left(7\right.$ to $23^{\circ} \mathrm{C}$, average daily mean) of three cultivars of cabbage (viz., Abbott \& Cobb No. 5, Gourmet, and Market Prize) in the field (Fontem et al. 1991). For A. japonica, Alternaria leaf spot disease development at the particularly favored temperature of $23^{\circ} \mathrm{C}$ was correlated with disease development, while 13 to $31^{\circ} \mathrm{C}$ was correlated with spore germination and secondary conidial production for A. japonica (Rimmer et al. 2007). Disease from A. japonica was first reported on turnip cultivar Virtudes-Martillo (B. rapa subsp. rapa) in fields of Alicante Province in Spain when the temperature ranged from 20 to $30^{\circ} \mathrm{C}$ (Bassimba et al. 2013), and also on wild and cultivated rocket (Diplotaxis tenuifolia and Eruca vesicaria, respectively) under greenhouse conditions during autumn and winter in northern Italy (Garibaldi et al. 2011).

In Australia, canola production increased from 3,900,000 metric tons (t) in 2013-14 to 4,200,000 t in 2016-17 (AOF 2018). Quality mustard rape is also considered a promising oleaceous Brassica crop for low-rainfall Australian regions, where it was first grown commercially in 2007 as a more thermal and drought tolerant "juncea canola" (Elliott et al. 2015; Oram et al. 2005) along with smaller areas of condiment mustard rape (Oram et al. 2005). However, although Van de Wouw et al. (2016) and Al-lami et al. (2019a) both highlighted that Alternaria leaf spot occurs widely on canola in Australia, no information was available in relation to mustard rape. Furthermore, Al-lami et al. (2019a, 2020) showed that Alternaria leaf spot in Australia is not solely caused by A. brassicae but also by a range of other Alternaria spp., including A. japonica, which displayed variation in relative levels of virulence. A. japonica was never previously studied in terms of disease development on canola. More importantly, both $A$. brassicae and A. japonica caused adverse field yield losses of $>58 \%$ on canola (Al-lami et al. 2019b). Hence, studies were undertaken into the effects of temperature $\left(14\right.$ and $10^{\circ} \mathrm{C}$ day and night, respectively, or 22 and $17^{\circ} \mathrm{C}$ day and night, respectively) on development of Alternaria leaf spot as relevant to A. japonica versus A. brassicae. We believe that these are the first studies to highlight the critical roles played by temperature for A. japonica as compared with A. brassicae in Alternaria leaf spot disease development and severity.

\section{Materials and Methods}

Alternaria isolates. A mixture of five different hyphal-tipped isolates of A. brassicae and six different hyphal-tipped isolates of $A$. japonica were used. All isolates were obtained during a southern Australian 2016 canola disease survey, and were chosen to represent a wide geographical area affected by Alternaria leaf spot. For A. brassicae, isolates utilized included three isolates (viz., WA-21.8, WA47.6, and WA-I) isolated from different locations in Western Australia (WA), a single isolate (SA-84.4) from South Australia (SA), and a single isolate (NSW-PSW.20) from New South Wales (NSW). For A. japonica, isolates utilizes included three isolates (viz., WA45.2.1, WA-46.8.A, and WA-47.1) from Western Australia derived from diseased canola leaves and three isolates (NSW-PSW.47, NSW-PSW.60, and NSW-PSW.77) from New South Wales collected from infected wild radish leaves. Isolates were chosen based on their high virulence either in tests conducted earlier on both canola cultivar Thunder TT and mustard rape cultivar Dune (Al-lami et al. 2019a) or in tests conducted for A. japonica isolates NSW-PSW.60 and NSWPSW.77 in another study (Al-lami et al. 2020). For each Alternaria $\mathrm{sp}$., isolates were mixed in equal proportions for use as inoculum to eliminate any potential pathotype-specific responses on the two inoculated test Brassica cultivars, as has been done with other Brassica pathogen studies such as Pseudocercosporella capsellae (Gunasinghe et al. 2017a,b) and Hyaloperonospora brassicae (Mohammed et al. 2017, 2018a), including temperature studies for the latter pathogen (Mohammed et al. 2018b).

Inoculum preparation and inoculation method. For production of hyphal inoculum, isolates were subcultured onto potato dextrose agar (PDA; Merck) for 7 days at $23 \pm 2{ }^{\circ} \mathrm{C}$ under cool white fluorescent light. Five agar discs of $4 \mathrm{~mm}^{2}$ containing growing mycelia from PDA were transferred into $150 \mathrm{ml}$ of liquid growth medium ( $24 \mathrm{~g}$ of potato dextrose broth and $10 \mathrm{~g}$ of peptone per liter of water) (Uloth et al. 2015a). Cultures were placed on a rotary shaker at $150 \mathrm{rpm}$ at $25^{\circ} \mathrm{C}$. After 5 days, actively growing mycelium was harvested by straining the broth through four layers of cheesecloth and washing well with sterile deionized water (SDW). The mycelium was macerated in SDW using a hand-held blender for 5 to $10 \mathrm{~min}$; the initial inoculum concentration was estimated using a hemocytometer counting chamber and then adjusted to obtain mycelial fragments of $90 \pm 10 \mu \mathrm{m}$ in length at a concentration of $4 \times 10^{6}$ fragments $/ \mathrm{ml}$ (Gunasinghe et al. 2017b). This hyphal inoculum was then used to initiate production of conidial inoculum as described below.

Production of conidial inoculum was carried out as described by Gunasinghe et al. (2017b) for the white leaf pathogen, P. capsellae. Seed of susceptible canola cultivar Thunder TT (Al-lami et al. 2019a) were sown in 7-by-7-by-18-cm pots (six seeds per pot), seedlings thinned to 1 plant per pot, and pots maintained at $22^{\circ} \mathrm{C}$ (day) and $18^{\circ} \mathrm{C}$ (night) in a controlled-environment room with a 12-h photoperiod. Plants were fertilized weekly with Thrive (Yates) at the manufacturer's recommended rate, a complete nutrient solution dissolved in water. At 6 weeks of age, plants were separated into two groups and spray inoculated with either a mixture of $A$. brassicae isolate mycelial suspension for one group or a mixture of $A$. japonica isolate mycelial suspension for the second group, using a hand-held and operated aerosol sprayer. Inoculated plants were covered with clear plastic bags for $96 \mathrm{~h}$ postinoculation (hpi) to maintain high humidity and misted with a SDW spray applied once per $24 \mathrm{~h}$ for 4 days. When disease symptoms became apparent, by approximately 7 to 14 days postinoculation (dpi), leaves with typical Alternaria leaf spot symptoms were collected and washed gently under SDW to remove any surface contamination. Lesions were then cut and placed into glass vials containing 20 to $30 \mathrm{ml}$ of SDW, and shaken vigorously by hand for $4 \mathrm{~min}$ to release conidia. The conidial mixture was then centrifuged for $5 \mathrm{~min}$ at $400 \times g$ and the supernatant discharged to concentrate conidia. Conidia were washed twice in SDW and resuspended in 2 to $3 \mathrm{ml}$ of SDW. Conidial concentration was adjusted to $5 \times 10^{5}$ $\mathrm{ml}^{-1}$ using a hemocytometer counting chamber.

Effect of two different temperature regimes on Alternaria leaf spot disease. Two susceptible Brassica sp. genotypes, canola cultivar Thunder TT and mustard rape cultivar Dune (Al-lami et al. 2019a), were used for each pathogen (A. japonica and A. brassicae). Four seeds each per pot were sown in 6-by-6-by-9-cm pots; seedlings were thinned to one plant per pot after germination. Plants were maintained at $22^{\circ} \mathrm{C}$ (day) and $18^{\circ} \mathrm{C}$ (night) in a controlledenvironment room with a 12-h day length and fertilized weekly with Thrive, as described above. Seven days after seedling emergence, half of the pots were shifted into a growth chamber maintained at 14 and $10^{\circ} \mathrm{C}$ day and night, respectively, and the other half into a growth chamber at 22 and $17^{\circ} \mathrm{C}$ day and night, respectively, with average RH of $70 \%$ in both chambers. These temperatures were similar to those used by Mohammed et al. (2018b) for temperature studies with the downy mildew pathogen $\mathrm{H}$. brassicae. Plants in both chambers were placed into clear plastic boxes $(770$ by 570 by $475 \mathrm{~mm}$, length by width by height) with lids; 2 days later, cotyledons (embryonic leaves) were drop inoculated $(10 \mu \mathrm{l})$, two drops per leaf, with the conidial inoculum $\left(5 \times 10^{5} \mathrm{ml}^{-1}\right)$ of either pathogen (or SDW as a negative control check). At 21 days after sowing, the true leaves (first leaves) were also inoculated with either pathogen (or SDW). Plastic boxes were internally misted with deionized water and lids closed for 96 hpi to maintain high humidity (wet period duration). Disease 
reactions on cotyledons and true leaves were recorded at 14 dpi to accommodate the slower disease development at 14 and $10^{\circ} \mathrm{C}$.

Disease assessment. A 0-to-5 scale developed by Kolte (1999) was used to assess the disease, where $0=$ no visible symptoms, $1=1$ to $10 \%$ leaf or pod area covered with small spots, $2=11$ to $25 \%$ leaf or pod area covered with spots $>3 \mathrm{~mm}, 3=26$ to $50 \%$ leaf or pod area covered with spots $>3 \mathrm{~mm}$ but with initiation of coalescing of lesions on leaves and deep lesions on pods, $4=51$ to $75 \%$ leaf or pod area covered with commonly coalescing lesions, and $5=76$ to $100 \%$ leaf or pod area covered with very large spots producing a typical blighted appearance. Each 0-to-5 diseased leaf score was converted into a percent cotyledon disease index (\%CDI) or percent true leaf disease index (\%TDI), with each disease index (DI) calculated based on the method described by McKinney (1923), where \%DI = $\{[(a \times 0)+(b \times 1)+(c \times 2)+\ldots(f \times 5)] \times 100\} /[(a+b+c+\ldots f) \times 5]$ and where $a, b, c, \ldots f$ are the number of plants with severity scores of $0,1,2, \ldots 0.5$, respectively.

Experiment design and statistical analyses. The experiment was fully repeated once. Each experiment had 10 replicates arranged in a randomized complete block design by using the 'Generate a Standard Design' function of GenStat Release 18.1 (VSNi 2019). A ShapiroWilk test was conducted to test the normality of the data and showed nonnormal distribution. Although several logarithmic transformations were conducted to normalize the data, they failed to apply normality to the data. Therefore, nonparametric analyses were performed using XLSTAT. The homogeneity of initial and repeat experiments was assessed using a Mann-Whitney $U$ test. These tests showed no significant difference $(P>0.05)$ between initial and repeated experiment data; hence, data sets from initial and repeat experiments were combined and reanalyzed as a single data set. Friedman's test was performed to calculate means and $P$ value of variables. Multiple pairwise comparisons were made using the Nemenyi procedure and two-tailed test (Hollander and Wolfe 1999; Nemenyi 1963).

\section{Results}

Symptoms. At 14 and $10^{\circ} \mathrm{C}$, the first appearance of Alternaria leaf spot symptoms from A. japonica on canola was 3 dpi, with $40 \%$ of true leaves showing symptoms after 8 dpi; however, 25 and $5 \%$ of cotyledons and true leaves, respectively, never showed any disease symptoms. On mustard rape, the first appearance of the symptoms was 8 dpi across different foliage components but only $20 \%$ of cotyledons showed symptoms after 3 dpi and $15 \%$ of true leaves showed no symptoms. For $A$. brassicae, the first appearance on both host species was at 3 dpi across different foliage components, with $5 \%$ of cotyledons of canola showing symptoms after 8 dpi but with $45 \%$ of cotyledons showing a hypersensitive reaction at that same time period. At 22 and $17^{\circ} \mathrm{C}$, the first appearance of Alternaria leaf spot of either pathogen (A. brassicae or A. japonica) on both host species and across different foliage components was $3 \mathrm{dpi}$. With both $A$. japonica and $A$. brassicae, the lesions appeared as gray to dark-gray in color at different temperatures but with an associated chlorotic effect at 22 and $17^{\circ} \mathrm{C}$ (Fig. 1).

Cotyledons versus true leaves and their response in relation to canola and mustard rape. Data showed no significant difference at $P \leq 0.05$ between canola (mean $\% \mathrm{DI}=57.6$ ) and mustard rape (mean \%DI $=57.4$ ) (Fig. 2A). There was a statistically significant difference at $P=0.015$ between foliage components. Cotyledons showed overall more disease (overall mean of \%CDI $=61.5$ ) compared with the true leaves (\%TDI =53.5) (Fig. 2B). Subsequently, a significant difference at $P<0.001$ was noted in cotyledons and true leaves across host species. On canola, the true leaves exhibited the greatest overall mean \%DI (61.6) compared with \%DI $=53.7$ for cotyledons. In contrast, cotyledons of mustard rape showed the greatest \%DI (69.4) compared with the true leaves $(\% \mathrm{DI}=45.3)$ (Fig. 2E).

Virulence of pathogens. There was a statistically significant difference at $P<0.001$ across pathogens. A. japonica caused less disease (overall mean $\% \mathrm{DI}=49.9$ ) compared with $A$. brassicae $(\% \mathrm{DI}=65.0)($ Fig. $2 \mathrm{C})$, and there was a statistically significant difference at $P<0.001$ between pathogens in terms of their virulence on canola and mustard rape, where A. japonica caused the most disease on canola $(\% \mathrm{DI}=58.3)$ as compared with mustard rape $(\% \mathrm{DI}=41.6)$, whereas $A$. brassicae caused more disease on mustard rape $(\% \mathrm{DI}=73.1)$ than on canola $(\% \mathrm{DI}=57.0)($ Fig. $2 \mathrm{~F})$. In
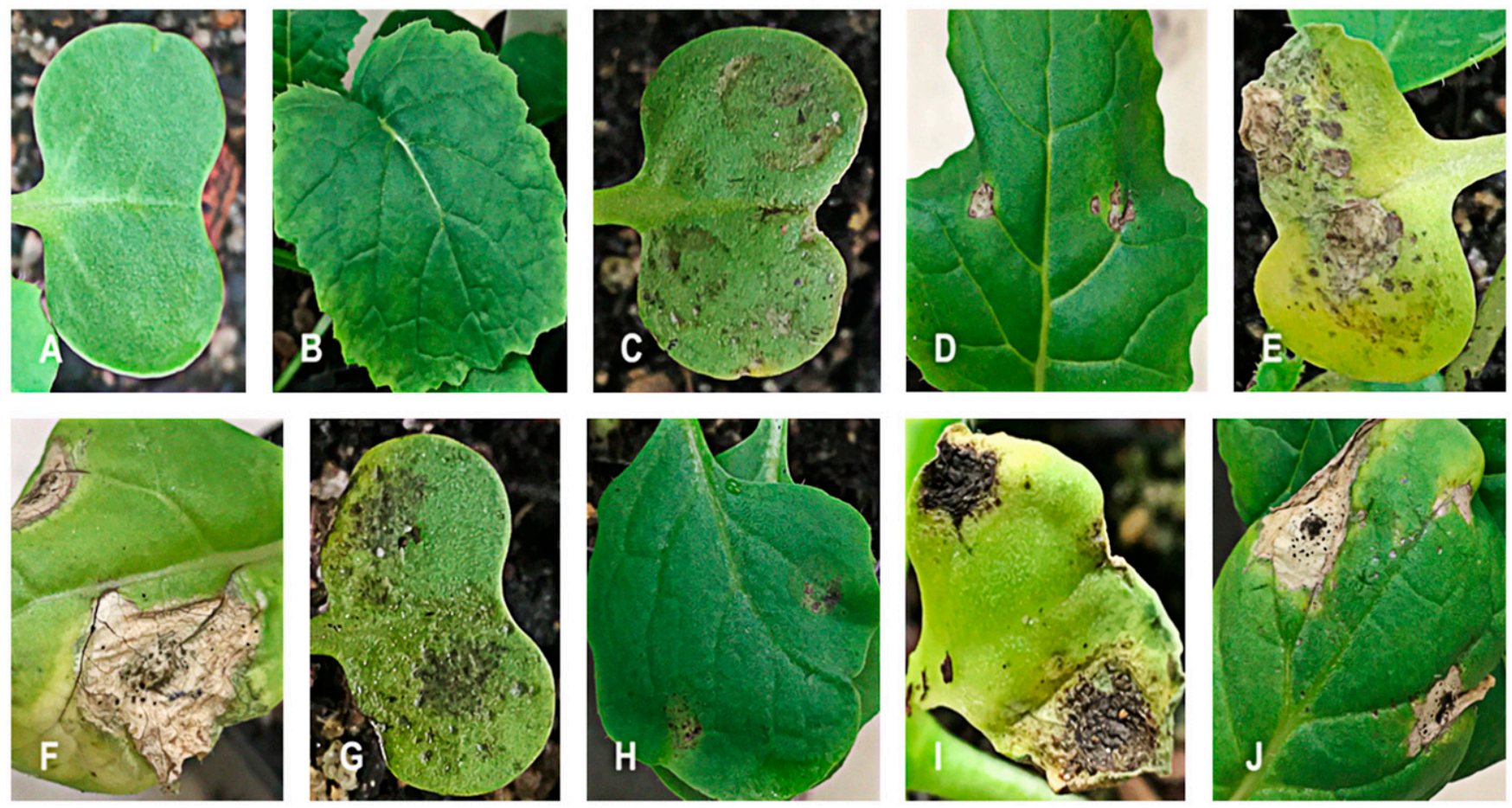

Fig. 1. Alternaria leaf spot disease symptoms on canola (Brassica napus 'Thunder TT') at different temperatures under controlled environmental conditions. A and B, Negative control of cotyledons and true leaves, respectively (inoculated with sterile deionized water). $\mathbf{C}$ and $\mathbf{D}$, Alternaria brassicae on cotyledons and true leaves at 14 and $10^{\circ} \mathrm{C}$. E and $\mathbf{F}, A$ brassicae on the same foliage components, respectively, at 22 and $17^{\circ} \mathrm{C} . \mathbf{G}$ and $\mathbf{H}, A$. japonica on the same foliage components, respectively, at 14 and $10^{\circ} \mathrm{C}$. I and $\mathrm{J}, A$. japonica on the same foliage components, respectively, at 22 and $17^{\circ} \mathrm{C}$. 
terms of the foliage component at the $P<0.001$ significance level, $A$. japonica caused more disease on cotyledons (\%CDI $=59.0$ ) than on true leaves $(\% \mathrm{TDI}=40.9)$. In contrast, $A$. brassicae caused more disease on true leaves $(\%$ TDI $=66.1$ ) compared with cotyledons $(\% \mathrm{CDI}=64.0)$ (Fig. $2 \mathrm{G})$. In relation to host species across different foliage components at the $P<0.001$ significance level, A. japonica caused severe disease on cotyledons of canola $(\%$ $\mathrm{CDI}=63.1)$ and mustard rape $(\% \mathrm{CDI}=54.9)$ and on the true leaves of canola $(\%$ TDI $=53.4)$, whereas the least disease was on the true leaves of mustard rape $(\% \mathrm{TDI}=28.31)$. In contrast, for A. brassicae, disease was most severe on cotyledons of mustard rape $(\% \mathrm{CDI}=83.8)$ and on true leaves of both canola $(\%$ TDI $=69.7)$ and mustard rape $(\%$ TDI $=62.4)$, whereas canola cotyledons showed the least disease $(\% \mathrm{CDI}=44.2)$ (Fig. 2N).

Day and night temperatures of 14 and $10^{\circ} \mathrm{C}$, respectively, versus 22 and $17^{\circ} \mathrm{C}$, respectively, and their influence on pathogen. Across the two temperatures at the $P<0.001$ significance level, lower temperatures (14 and $10^{\circ} \mathrm{C}$ day and night, respectively) resulted in the least disease (mean $\% \mathrm{DI}=30.4$ ) compared with $\%$ $\mathrm{DI}=84.5$ at the higher temperatures $\left(22\right.$ and $17^{\circ} \mathrm{C}$ day and night, respectively) (Fig. 2D). The disease severity across low and high temperatures showed similarity between A. japonica and A. brassicae; both caused significantly less disease at 14 and $10^{\circ} \mathrm{C}(\%$ DI values of 19.1 and 41.8 , respectively) as compared with more severe disease at 22 and $17^{\circ} \mathrm{C}$ (\%DI values 80.8 and 88.2, respectively) (Fig. 2I).

Influence of temperature on foliage components of canola and mustard rape. At the $P<0.001$ significance level, cotyledons and true leaves at the higher temperature exhibited more disease
$(\% \mathrm{DI}=88.6$ and 80.5 , respectively $)$ compared with the lower temperature (\%DI $=34.5$ and 26.4 , respectively) (Fig. $2 \mathrm{~J})$. At the lower temperature, both host species showed the least disease with mean \%DI = of 27.3 and 33.5 for canola and mustard rape, respectively, as compared with the higher temperatures, where there was a greater disease incidence with $\% \mathrm{DI}=$ values of 87.9 and 81.2 for these same host species, respectively, (Fig. $2 \mathrm{H})$. In relation to different foliage components across cultivars at the $P<0.001$ significance level, cotyledons and true leaves expressed more disease across cultivars at 22 and $17^{\circ} \mathrm{C}$ day and night, respectively, compared with the low disease incidence of the same foliage components at 14 and $10^{\circ} \mathrm{C}$. On canola, the disease severity on cotyledons and true leaves $(\% \mathrm{DI}=84.9$ and 90.9, respectively) was greater at the higher temperatures compared with the lowest \%DI values of 22.44 and 32.3, respectively, at the lower temperatures (Fig. 2M). Similarly, on mustard rape, the highest \%DI values on cotyledons and true leaves $(\% \mathrm{DI}=92.2$ and 70.2 , respectively) were at the higher temperatures compared with \%DI values of 46.6 and 20.5 , respectively, at the lower temperatures.

Influence of temperature on disease severity across different foliage components of canola and mustard rape. At the $P<$ 0.001 significance level, the disease severity of either $A$. japonica or A. brassicae was much less at 14 and $10^{\circ} \mathrm{C}$ compared with 22 and $17^{\circ} \mathrm{C}$ across different foliage components. At 14 and $10^{\circ} \mathrm{C}, A . j a-$ ponica displayed very low \%DI values of 22.6 and 15.5 on cotyledons and true leaves, respectively, as compared with at 22 and $17^{\circ} \mathrm{C}$, where there were much greater \%DI values of 95.4 and 66.2 on these same foliage components, respectively (Fig. 2K). Similarly,
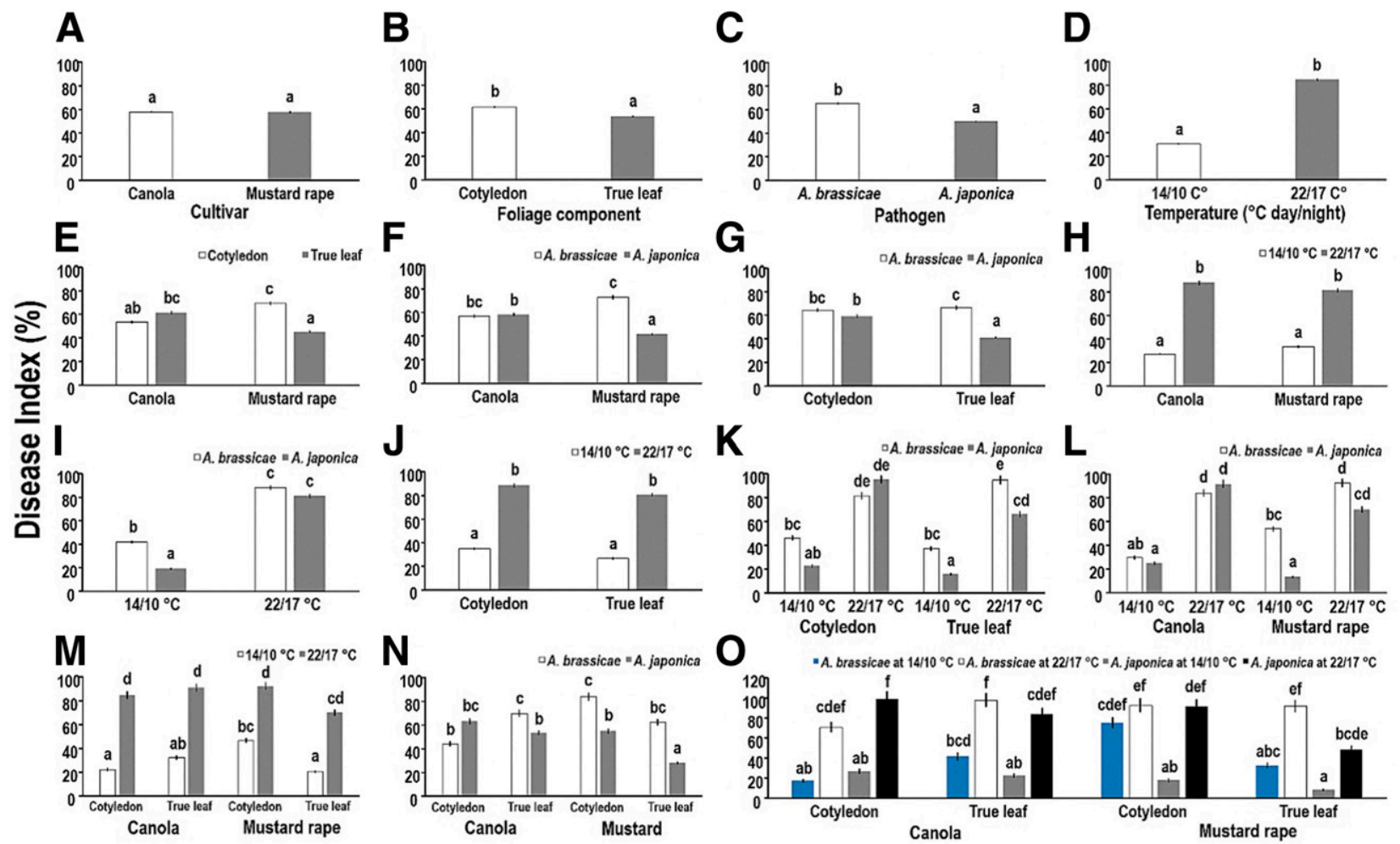

Fig. 2. Impact of two different temperatures $\left(14\right.$ and $10^{\circ} \mathrm{C}$ day and night, respectively, versus 22 and $17^{\circ} \mathrm{C}$ day and night, respectively) on Alternaria leaf spot development caused by Alternaria japonica versus A. brassicae across different foliage components (cotyledons and true leaves) of canola (Brassica napus 'Thunder TT') and mustard rape (B. juncea 'Dune') at 14 days postinoculation. Data represent means \pm standard deviation of disease incidence (\%) in relation to $\mathbf{A}$, host species or cultivar; $\mathbf{B}$, foliage component; $\mathbf{C}$, pathogen; D, temperature; E, cotyledons and true leaves across cultivars; F, A. brassicae and A. japonica across cultivars; $\mathbf{G}, A$. brassicae and $A$. japonica across different foliage components; $\mathbf{H}, 14$ and $10^{\circ} \mathrm{C}$ day and night, respectively, versus 22 and $17^{\circ} \mathrm{C}$ day and night, respectively, across cultivars; I, A. brassicae and $A$. japonica at low and high temperatures; $\mathbf{J}, 14$ and $10^{\circ} \mathrm{C}$, respectively, versus 22 and $17^{\circ} \mathrm{C}$ day and night, respectively, across foliage components; $\mathbf{K}, A$. brassicae and $A$. japonica at low and high temperatures on cotyledons and true leaves; L, A. brassicae and A. japonica at low and high temperatures across cultivars; $\mathbf{M}$, influence of low and high temperatures on cotyledons and true leaves of canola and mustard rape; $\mathbf{N}$, pathogenic capability of both pathogens on cotyledons and true leaves of canola and mustard rape; and $\mathbf{0}$, disease development at low and high temperature in relation to foliage components of canola and mustard rape. Bars labeled with different letters across factors show the significant difference with multiple pairwise comparisons using Nemenyi's procedure and two-tailed test at $P<0.05$. 
A. brassicae showed relatively low \%DI values of 46.3 and 37.3 on cotyledons and true leaves, respectively, at 14 and $10^{\circ} \mathrm{C}$ as compared with 22 and $17^{\circ} \mathrm{C}$, where the \%DI values were 81.7 and 94.8 for the same foliage components, respectively. Subsequently, in relation to the virulence of two pathogens across host species at the $P<0.001$ significance level, A. japonica caused more disease on canola $(\%$ $\mathrm{DI}=91.6)$ compared with mustard rape $(\% \mathrm{DI}=70.1)$ at 22 and $17^{\circ} \mathrm{C}$, whereas $A$. brassicae caused more disease on mustard rape $(\% \mathrm{DI}=92.3)$ compared with canola $(\% \mathrm{DI}=84.2)$ at the same high temperatures. At 14 and $10^{\circ} \mathrm{C}$, despite both $A$. japonica and A. brassicae causing significantly less disease on mustard rape $(\% \mathrm{DI}=13.2$ and 53.9, respectively) and canola (\%DI $=24.9$ and 29.7, respectively), A. brassicae showed more disease on mustard rape and canola compared with $A$. japonica (Fig. 2L).

Disease development at low and high temperatures in relation to foliage components of canola and mustard rape. There was significant difference at $P<0.001$ in terms of the effect of the two pathogens at low and high temperatures on different foliage components across host species. At the lower temperature, cotyledons $(\% \mathrm{CDI}=$ 27.1 and 17.6) and true leaves (\%TDI $=22.7$ and 41.9) of canola showed less disease from A. japonica and A. brassicae (Fig. 2O). On mustard rape, low disease incidence was also observed on cotyledons $(\% \mathrm{CDI}=18.1$ from $A$. japonica $)$ and the true leaves $(\% \mathrm{TDI}=$ 8.2 and 32.7 from A. japonica and A. brassicae, respectively). However, at higher temperatures, the disease severity was significantly greater. On canola and mustard rape, high disease severity was observed across different foliage components; namely, cotyledons $(\%$ $\mathrm{CDI}=99.1$ and 70.7 for canola and \%CDI $=91.7$ and 92.6 for mustard rape) and true leaves (\%TDI $=84.1$ and 97.6 for canola and \% TDI $=48.4$ and 92.0 for mustard rape) from $A$. japonica and A. brassicae, respectively. Cotyledons of mustard rape showed more disease $(\% \mathrm{CDI}=75.0)$ from $A$. brassicae at the lower temperatures but expressed greater disease at the higher temperatures $(\% \mathrm{CDI}=$ 92.6) (Fig. 2O). Subsequently, there was significant difference at $P<0.0001$ in terms of the effect of the two pathogens on cotyledons of mustard rape at the low temperatures; A. japonica produced less disease $(\% \mathrm{CDI}=18.1)$ as compared with more disease $(\% \mathrm{CDI}=$ 75.0) from A. brassicae (Fig. 2O).

\section{Discussion}

We believe that these are the first studies to highlight the critical roles played by temperature for A. japonica as compared with A. brassicae in Alternaria leaf spot disease development and severity on canola and mustard rape. A. brassicae is globally considered the most significant Alternaria sp. on canola and has been widely studied for infection requirements as related to different temperatures, $\mathrm{RH}$, and host age (Humpherson-Jones and Phelps 1989; Saharan et al. 2016). In contrast, $A$. japonica has not been previously studied in terms of disease development on canola or mustard rape. Because both diseases co-occur on canola in Australia (Al-lami et al. 2019a), it was important that comparison be made between A. japonica and A. brassicae. Furthermore, for Australia, prior to this study, there was little understanding as relates to temperature for $A$. brassicae in terms of disease severity on canola or mustard rape. A. brassicae has been widely highlighted as a major and common pathogen of oilseed Brassicas, while A. alternata, A. brassicicola, and A. raphani are of more concern in relation to vegetable crops (Saharan et al. 2016). However, A. japonica was not only isolated from surveys of canola crops across southern Australia in 2016 (M. P. You and M. J. Barbetti, unpublished data) but was pathogenic on both canola and mustard rape (Al-lami et al. 2019a). The current study emphasizes the potential for A. japonica to become a significant pathogen on members of the Brassicaceae family, along with the previously described Alternaria spp. pathogens, especially because A. japonica is pathogenic on both Brassicaceae and non-Brassicaceae hosts, both in Australia and elsewhere (Farr and Rossman 2019).

The current study revealed how temperature affects the development and severity of Alternaria leaf spot caused by A. japonica on both canola and mustard rape, as compared with A. brassicae. Although the effect of temperature showed significant differences across tested variables, including host species, foliage component, and pathogen, temperature was a dominant determinant of disease development by A. japonica, as it is with A. brassicae. At the lower temperatures, despite $A$. brassicae being highly pathogenic on cotyledons of mustard rape, neither pathogen caused severe disease until the temperature increased; however, this effect was not independent of foliage component or the causal Alternaria sp. Degenhardt et al. (1982), working with different pathotypes of three Alternaria spp. also noticed a strong effect of different temperatures $(11,15,19$, 23 , and $27^{\circ} \mathrm{C}$ ) on the third leaf of 4-week-old canola cultivar Zephyr and that the effect was dependent on the Alternaria sp. They found that $A$. brassicae was pathogenic across these different temperatures, that $A$. raphani was pathogenic at $17^{\circ} \mathrm{C}$ and above, that $A$. brassicicola was pathogenic at $19^{\circ} \mathrm{C}$ and above; and that most severe disease was at 19 to 23,23 , and 23 to $25^{\circ} \mathrm{C}$ for $A$. brassicae, A. raphani, and A. brassicicola, respectively. Likewise, Fontem et al. (1991) observed similar effects of different temperatures (spring and winter seasons) on three cultivars of cabbage (Abbott \& Cobb No. 5, Gourmet, and Market Prize) in the field from A. brassicicola. They distinguished the disease progression and epidemic development between spring $\left(17\right.$ to $32^{\circ} \mathrm{C}$, average daily mean) and winter $\left(7\right.$ to $23^{\circ} \mathrm{C}$, average daily mean) seasons, with area under disease progress curve values of 13.0, 24.6, and 25.7 in spring, and 7.7, 8.5, and 12.3 in winter for the same cultivars, respectively. They showed that the disease epidemic was slower in winter than in warmer springtime. Furthermore, Mridha and Wheeler (1993) noted that, although optimal infection temperature of $A$. brassicae on $B$. napus 'Jet Neuf' third, fourth, and fifth leaves was $25^{\circ} \mathrm{C}$, infection also was observed at 15,20 , and $29^{\circ} \mathrm{C}$, with very slight infections at $10^{\circ} \mathrm{C}$. Bassimba et al. (2013) first reported A. japonica leaf spot on turnip in Alicante Province in Spain when the temperature ranged from 20 to $30^{\circ} \mathrm{C}$, with approximately $20 \%$ disease infestation. Furthermore, Garibaldi et al. (2011) first reported A. japonica leaf spot on wild and cultivated rocket under greenhouse conditions during autumn and winter in northern Italy, with 30 to $40 \%$ disease infestation. Moreover, Rimmer et al. (2007) demonstrated that a temperature of $23^{\circ} \mathrm{C}$ was correlated with disease development and 13 to $31^{\circ} \mathrm{C}$ was correlated with spore germination and secondary conidial production for A. japonica. In contrast, Humpherson-Jones and Phelps (1989) illustrated that temperature ranging from 5 to $30^{\circ} \mathrm{C}$ resulted in no significant differences in the average sporulation duration of A. brassicae in lesions generated on canola cultivar Bienvenue or sweede cultivar Best of All. Despite this, in general, the abundance of spores likely increased the disease epidemic in field crops once the favorable conditions for infection were available. Alternaria leaf spot development and severity caused by A. brassicae disease on species of Brassicaceae is strongly affected by environmental conditions (Awasthi and Kolte 1990; Bal and Kumar 2014; Chattopadhyay et al. 2005; Selvamani et al. 2014) and this likely explains the highly variable nature of Alternaria leaf spot epidemics, including in Australia, regardless of the Alternaria spp. involved.

The current study not only highlights how temperature, host species, and foliage component influence Alternaria leaf spot development on oilseed Brassicas but also shows that this occurs across different species of Alternaria (namely, A. japonica as compared with $A$. brassicae). Despite A. japonica not being as pathogenic at lower temperatures on either cotyledons or true leaves across tested cultivars, the greater disease incidence in the current study of mustard rape from $A$. brassicae at an earlier stage (cotyledons) and at lower temperatures implies both a greater overall crop risk of severe infection by the latter species and its ability to be a significant inoculum source for infecting other oilseed and horticultural crops growing in the same vicinity. In Australia, the Mediterranean regions of southwestern and southern Australia are highly variable in terms of environmental conditions, and this variability greatly and differentially influences the development of a range of Brassica diseases (Barbetti et al. 2012). That Alternaria spp. are not generally regarded as particularly major pathogens of oilseed Brassicas in Australia is likely due to these variable environmental conditions, which are less conducive to epidemics there than in some other countries 
such as India, where Alternaria leaf spot is considered a very serious and, at times, almost "unmanageable disease" (Chattopadhyay et al. 2005; Saharan et al. 2016). However, the finding that $A$. japonica and $A$. brassicae infections in both canola and mustard rape were favored by warmer temperatures in the current study is important for both crops, because temperatures readily reach or exceed 18 to $24^{\circ} \mathrm{C}$ during the latter part of the growing season in many regions in Australia and worldwide. Furthermore, temperature affects the disease severity of a range of other Brassicaceae diseases. Among other examples, Li et al. (2006) highlighted how Phoma stem canker (blackleg; Leptosphaeria maculans) is strongly influenced by temperature, with more severe crown canker at higher temperatures $\left(18\right.$ to $\left.24^{\circ} \mathrm{C}\right)$ compared with lower temperatures $\left(11\right.$ to $\left.18^{\circ} \mathrm{C}\right)$; Mohammed et al. (2018b) studied downy mildew at 22 and $17^{\circ} \mathrm{C}$ versus 14 and $10^{\circ} \mathrm{C}$ and showed that higher temperatures accelerated the disease severity, well illustrated with B. napus 'Atomic' that showed less disease at 14 and $10^{\circ} \mathrm{C}$ but greater disease at 22 and $17^{\circ} \mathrm{C}$; and Uloth et al. (2018) studied powdery mildew development and severity on different $B$. napus cultivars and found a similar pattern of high disease severity at 22 and $17^{\circ} \mathrm{C}$ compared with low disease severity at 14 and $10^{\circ} \mathrm{C}$. These latter studies on other Brassicaceae pathogens highlight the concern that temperature increases from climate change will increase severity of some Brassicaceae diseases, as highlighted earlier by Barbetti et al. (2012). It is likely that the same applies for Alternaria leaf spot under future warming climate predictions for Australia and elsewhere. However, it remains to be determined if there are temperature phenotypes for A. japonica or A. brassicae as exist for Sclerotinia sclerotiorum where, for example, isolates collected from warmer or cooler areas show adaptation to higher or lower temperatures, respectively, when infecting B. carinata (Uloth et al. 2015b).

In conclusion, this study demonstrates the important influence of temperature across different Brassica host species and foliage components on the development and severity of Alternaria leaf spot caused by $A$. japonica versus $A$. brassicae. The findings show that disease severity from $A$. japonica increases with warmer temperatures and decreases with colder temperatures, as in A. brassicae, but the cold temperature effect was not independent of host species, foliage component, or causal Alternaria sp. Furthermore, the current study suggests likely greater Alternaria leaf spot development and severity in future decades during the spring season across southern Australia, where temperatures are rising due to climate change (Barbetti et al. 2012). In addition, precautions are needed for canola and mustard rape breeders to avoid inadvertently selecting for genotypes more susceptible to one or more Alternaria spp., as can easily occur in screening programs intently focused on maximizing resistance to blackleg and where other diseases are "masked" by extremely severe blackleg. The increasing temperatures along with any inadvertent selection for heightened susceptibility to A. japonica or A. brassicae would significantly enhance their opportunity to become much more important and damaging pathogens to both canola and mustard rape.

\section{Acknowledgments}

We thank the Grains Research and Development Corporation project GRDC UWA 170 "Emerging foliar diseases of canola" for allowing access to some survey samples to collect pathogen isolates and R. Creasy and B. Piasini at the University of Western Australia (UWA) Plant Growth Facilities for their technical assistance in plant growth facilities at UWA.

\section{Literature Cited}

Al-lami, H. F. D., You, M. P., and Barbetti, M. J. 2019a. Incidence, pathogenicity and diversity of Alternaria spp. associated with Alternaria leaf spot of canola (Brassica napus) in Australia. Plant Pathol. 68:492-503.

Al-lami, H. F. D., You, M. P., and Barbetti, M. J. 2019b. Role of foliage component and host age on Alternaria leaf spot (caused by Alternaria japonica and A. brassicae) in canola (Brassica napus) and mustard (B. juncea) and yield loss in canola. Crop Pasture Sci. 70:969-980.

Al-lami, H. F. D., You, M. P., Mohammed, A. E., and Barbetti, M. J. 2020. Virulence variability across the Alternaria spp. population determines incidence and severity of Alternaria leaf spot on rapeseed. Plant Pathol. In press. doi:10.1111/ppa.13135
AOF. 2018. Australian Oilseeds Federation Crop Reports. www.australianoilseeds. com/oilseeds_industry/crop_report_assets

APPD. 2019. Australian Plant Pest Database. Plant Health Australia. https:// www.planthealthaustralia.com.au/resources/australian-plant-pest-database/

Awasthi, R. P., and Kolte, S. J. 1990. Effect of some epidemiological factors on occurrence and severity of Alternaria blight of rapeseed and mustard. Pages 49-55 in: Oil Crops: Proc. Three Meet. Pantnagar and Hyderabad, India.

Bal, R. S., and Kumar, A. 2014. Studies on the epidemiology of white rust and Alternaria leaf blight and their effect on the yield of Indian mustard. Afr. J. Agric. Res. 9:302-306.

Barbetti, M. J., Banga, S. S., and Salisbury, P. A. 2012. Challenges for crop production and management from pathogen biodiversity and diseases under current and future climate scenarios-case study with oilseed Brassicas. Field Crops Res. 127:225-240.

Bassimba, D. D. M., Mira, J. L., and Vicent, A. 2013. First report of Alternaria japonica causing black spot of turnip in Spain. Plant Dis. 97:1505.

Brazauskiene, I., and Petraitiene, E. 2006. The occurrence of Alternaria blight (Alternaria spp.) and Phoma stem canker (Phoma lingam) on oilseed rape in central Lithuania and pathogenic fungi on harvested seed. J. Plant Prot. Res. 46:295-311.

Chattopadhyay, C., Agrawal, R., Kumar, A., Bhar, L. M., Meena, P. D., Meena, R. L., Meena, R., Khan, S. A., Chattopadhyay, A. K., Awasthi, R. P., Singh, S. N., Chakravarthy, N. V. K., Kumar, A., Singh, R. B., and Bhunia, C. K. 2005. Epidemiology and forecasting of Alternaria blight of oilseed Brassica in India-a case study. J. Plant Dis. Prot. 112:351-365.

Degenhardt, K. J., Petrie, G. A., and Morrall, R. A. A. 1982. Effects of temperature on spore germination and infection of rapeseed by Alternaria brassicae, A. brassicicola, and A. raphani. Can. J. Plant Pathol. 4:115-118.

Degenhardt, K. J., Skoropad, W. P., and Kondra, Z. P. 1974. Effects of Alternaria blackspot on yield, oil content and protein content of rapeseed. Can. J. Plant Sci. 54:795-799.

Elliott, V. L., Norton, R. M., Khangura, R. K., Salisbury, P. A., and Marcroft, S. J. 2015. Incidence and severity of blackleg caused by Leptosphaeria spp. in juncea canola (Brassica juncea L.) in Australia. Australas. Plant Pathol. 44: 149-159.

Evans, E. J., and Gladders, P. 1981. Diseases of winter oilseed rape and their control, East and South-East England, 1977-81. Pages 505-512 in: Proc. Int. Crop Prot. Conf., 1981.

Farr, D. F., and Rossman, A. Y. 2019. Fungal Databases, U. S. National Fungus Collections. United States Department of Agriculture-Agricultural Research Service. https://nt.ars-grin.gov/fungaldatabases/

Fontem, D. A., Berger, R. D., Weingartner, D. P., and Bartz, J. A. 1991. Progress and spread of dark leaf spot in cabbage. Plant Dis. 75:269-274.

Garibaldi, A., Gilardi, G., Bertoldo, C., and Gullino, M. L. 2011. First report of leaf spot of wild (Diplotaxis tenuifolia) and cultivated (Eruca vesicaria) rocket caused by Alternaria japonica in Italy. Plant Dis. 95:1316.

Gunasinghe, N., You, M. P., Banga, S. S., Banga, S. K., and Barbetti, M. J. 2017 a. Outstanding host resistance will resolve the threat from white leaf spot disease (Pseudocercosporella capsellae) to oilseed and vegetable Brassica spp. crops. Australas. Plant Pathol. 46:137-146.

Gunasinghe, N., You, M. P., Clode, P., Cawthray, G. R., and Barbetti, M. J. 2017b. Unique infection structures produced by Pseudocercosporella capsellae on oilseed crops Brassica carinata, B. juncea and B. napus in Western Australia. Plant Pathol. 66:304-315.

Hollander, M., and Wolfe, D. A. 1999. Nonparametric Statistical Methods. Wiley, Chichester, U.K.

Humpherson-Jones, F. M., and Maude, R. B. 1982. Studies on the epidemiology of Alternaria brassicicola in Brassica oleracea seed production crops. Ann. Appl. Biol. 100:61-71.

Humpherson-Jones, F. M., and Phelps, K. 1989. Climatic factors influencing spore production in Alternaria brassicae and Alternaria brassicicola. Ann. Appl. Biol. 114:449-458.

Kolte, S. J. 1999. Methods of inoculation for resistance to Alternaria blight of rapeseed and mustard. J. Mycol. Plant Pathol. 29:96-99.

Kumar, A. 1997. Assessment and economics of avoidable yield losses due to Alternaria blight in oilseed Brassicas. Plant Dis. Res. 12:152-156.

Li, H., Smyth, F., Barbetti, M. J., and Sivasithamparam, K. 2006. Relationship between Brassica napus seedling and adult plant responses to Leptosphaeria maculans is determined by plant growth stage at inoculation and temperature regime. Field Crops Res. 96:428-437.

Marchegay, P., Thorin, N., and Schiavon, M. 1990. Effets des facteurs climatiques sur l'émission aérienne des spores d'Alternaria brassicae (Berk) Sacc et sur l'épidémiologie de l'alternariose dans une culture de colza. Agronomie 10: 831-839.

McKinney, H. H. 1923. Influence of soil temperature and moisture on infection of wheat seedlings by Helminthosporium sativum. J. Agric. Res. 26:195-218.

Meena, P. D., Awasthi, R. P., Chattopadhyay, C., Kolte, S. J., and Kumar, A. 2010 Alternaria blight: A chronic disease in rapeseed-mustard. J. Oilseed Brassica 1: $1-11$.

Mohammed, A. E., You, M. P., Al-lami, H. F. D., and Barbetti, M. J. 2018a. Pathotypes and phylogenetic variation determine downy mildew epidemics in Brassica spp. in Australia. Plant Pathol. 67:1514-1527. 
Mohammed, A. F., You, M. P., and Barbetti, M. J. 2017. New resistances offer opportunity for effective management of the downy mildew (Hyaloperonospora parasitica) threat to canola. Crop Pasture Sci. 68:234-242.

Mohammed, A. E., You, M. P., and Barbetti, M. J. 2018b. Temperature and plant age drive downy mildew disease epidemics on oilseed Brassica napus and B. juncea. Eur. J. Plant Pathol. 151:703-711.

Mridha, M. A. U., and Wheeler, B. E. J. 1993. In vitro effects of temperature and wet periods on infection of oilseed rape by Alternaria brassicae. Plant Pathol. 42:671-675.

Nemenyi, P. B. 1963. Distribution-free multiple comparisons (Doctoral Dissertation, Princeton University, 1963). Dissertation Abstr. Int. 25:1233.

Oram, R. N., Kirk, J. T. O., Veness, P. E., Hurlstone, C. J., Edlington, J. P., and Halsall, D. M. 2005. Breeding Indian mustard [Brassica juncea (L.) Czern.] for cold-pressed, edible oil production-A review. Aust. J. Agric. Res. 56: 581-596.

Prasad, R., Saxena, D., and Chandra, S. 2003. Yield losses by Alternaria blight in promising genotypes of Indian mustard. Indian Phytopathol. 56: 205-206.

Rimmer, S. R., Shattuck, V. I., and Buchwaldt, L., eds. 2007. Page 18 in: Compendium of Brassica Diseases. American Phytopathological Society Press, St. Paul, MN, U.S.A.

Saharan, G. S., and Kadian, A. K. 1983. Analysis of components of horizontal resistance in rape seed and mustard cultivars against Alternaria brassicae. Indian Phytopathol. 36:503-507.

Saharan, G. S., Mehta, N., Meena, P. D., and Dayal, P. 2016. Pages 6-266 in: Alternaria Diseases of Crucifers: Biology, Ecology and Disease Management. Springer Verlag, Singapore, Malaysia.
Sampson, P. J., and Walker, J. 1982. An Annotated List of Plant Diseases in Tasmania. Hobart, Australia. Department of Agriculture, Tasmania, Australia. Selvamani, R., Pandian, R. T. P., and Sharma, P. 2014. Role of weather on Alternaria leaf spot development in crucifers. Indian Phytopathol. 67:285-290.

Shivas, R. G. 1989. Fungal and bacterial diseases of plants in Western Australia J. R. Soc. West. Aust. 72:1-62.

Uloth, M. B., Clode, P. L., You, M. P., and Barbetti, M. J. 2015a. Attack modes and defence reactions in pathosystems involving Sclerotinia sclerotiorum, Brassica carinata, B. juncea and B. napus. Ann. Bot. 117:79-95.

Uloth, M. B., You, M. P., and Barbetti, M. J. 2018. Plant age and ambient temperature: Significant drivers for powdery mildew (Erysiphe cruciferarum) epidemics on oilseed rape (Brassica napus). Plant Pathol. 67:445-456.

Uloth, M. B., You, M. P., Cawthray, G., and Barbetti, M. J. 2015b. Temperature adaptation in isolates of Sclerotinia sclerotiorum affects their ability to infect Brassica carinata. Plant Pathol. 64:1140-1148.

Van de Wouw, A. P., Idnurm, A., Davidson, J. A., Sprague, S. J., Khangura, R. K., Ware, A. H., Lindbeck, K. D., and Marcroft, S. J. 2016. Fungal diseases of canola in Australia: Identification of trends, threats and potential therapies. Australas. Plant Pathol. 45:415-423.

Verma, P. R., and Saharan, G. S. 1994. Monograph on Alternaria diseases of crucifers. In: Saskatoon Research Centre Technical Bulletin 1994-6E Agriculture and Agri-Food Canada, Saskatoon, SK, Canada.

VSNi. 2019. GenStat Release 18.1, 18th ed. Lawes Agricultural Trust, Rothamsted Research, U.K.

You, M. P., Simoneau, P., Dongo, A., Barbetti, M. J., Li, H., and Sivasithamparam, K. 2005. First report of an Alternaria leaf spot caused by Alternaria brassicae on Crambe abyssinicia in Australia. Plant Dis. 89:430. 